\title{
ALK Negative
}

National Cancer Institute

\section{Source}

National Cancer Institute. ALK Negative. NCI Thesaurus. Code C133707.

Indicates that expression of ALK has not been detected in a sample. 